\section{The "Motivational Climate in Physical Education Scale" in Greek Educational Context: Psychometric Properties and Gender Effects}

\author{
Gregory Masadis ${ }^{a}$, Filippos Filippou ${ }^{b,{ }^{*}}$, Olga Koulic, \\ Dimitris Gargalianosd , Stella Rokka ${ }^{e}$, Evangelos Bebetsos ${ }^{f}$, \\ Vasiliki Derrig, Sofia Damianidout , Aikaterini Koupanii, \\ Eleni Samaraj, Dafni Siarenouk, Dafni-Anastasia Filippou'
}

$\begin{array}{ll}\text { Received: } & 28 \text { November } 2019 \\ \text { Revised: } \quad 27 \text { February } 2020 \\ \text { Accepted: } \quad 9 \text { March } 2020 \\ \text { ISSN: 1307-9298 } \\ \text { Copyright @ IEJEE } \\ \text { www.iejee.com }\end{array}$

DOI: 10.26822/iejee.2020459461

\title{
Abstract
}

The aim of this study was to carry out a preliminary validation of "Motivational Climate in Physical Education Scale" in Greek educational context and specifically in relation to elementary school students. The participants of the research were 184 (101 male and 83 female) students of grades 5th and 6th from four elementary schools, in different geographical areas of Greece. The Greek version of Motivational Climate in Physical Education Scale was used for the data collection. The statistical analyses that were applied included: descriptive analysis, exploratory factor analysis, reliability analysis and the One-way ANOVA analysis. The results showed that the questionnaire retains the structure of the four factors that its designers have recommended and the internal cohesion of the four factors was high (.85 the lowest and .90 the highest). Survey data revealed that the Greek version of the "Motivational Climate in Physical Education Scale" is a reliable tool for the measurement of motivational climate in the Greek educational elementary school environment, and the gender determines the climate of motivation with male students scoring higher in task involving and autonomy factors whereas female students perform better in task involving and relatedness.

Keywords: Motivational Climate, Students of Primary School, Physical Education Classes

\section{Introduction}

Physical education (PE) is an invaluable subject in primary and secondary school curricula because of its great potential for students' physical, mental, emotional, and social development (Bournelli, Koutsouki, Zografou, Aggelonidis, Chatzopoulos, \& Agalianou, 2012). The main objective that has been highly prioritized in school curricula in recent years has to do with lifelong physical exercise. In other words, the acquisition of knowledge and experience of physical training so that students will sustain good health after school (Hagger \& Chatzisarantis, 2007). During the school years, dealing with health issues promptly and efficiently is crucial (Institute of Educational Policy, 2014; Bournelli et al., 2012).

Despite tangible benefits that derive from PE and after-school sports activities, students, as they grow older, become more reluctant to participate and gradually spare no effort during PE lessons (Iconomescu, Mindrescu, \& Popovici, 2018; Ntoumanis, Barkoukis, \& Thøgersen-Ntoumani, 2009). The big challenge of PE teachers is whether and how they will succeed in convincing students to exert their energy on activities that fit them, how they will make the most of knowledge and experiences they gain, and finally in which way students come to be motivated for lifelong exercise (Fox, 1992). Therefore, the school climate and the rapport teachers build up with students are essential.

Parents' positive attitude toward school is another element that nourishes a climate of motivation because it influences the quality and quantity of students' interaction (Koun- douras, 2017). Additional contributing factors are character, school subject, and feedback (Parissi, Mouratidou, Koidou, Tsorbatzoudis, \& Karamavrou, 2015). According to Treasure and Roberts (1995), the motivational climate has six dimensions reflected on the acronym T-A-R-G-E-T, which stands for Task (classroom activities), Authority (for students to have a say in decision-making), Recognition (when students are prized), Grouping (learning to work together as a team), Evaluation (refers to assessment and feedback), Time (flexible time for task completion) Morgan (2017) supported that the relationship between educator/trainer and trainee should be further explored and that T-A-R-G-E-T should be modified to include "relationships" in the Recognition section.

However, as Colquitt, Walker, Langdon, McCollum, and Pomazal (2012) mentioned, PE's objective to provide an effective learning experience has been strongly criticized. PE teachers must thus know their students' attitude toward the subject, and in particular, its main components and target, and they must explore their students' individual learning needs to improve the learning process by exerting innovative teaching methods (Cid, Pires, Borrego, Duarte-Mendes, Teixeira, Moutão, \& Monteiro, 2019). Lastly, students' views on the subject are a key element in the whole assessment of the teaching procedure (Ghofrani \& Golsanamlou, 2012).

PE teachers are advised to have at their disposal a reliable measuring instrument of the motivational climate during the lesson to modify the flow of it through a range of activities. By doing so, they can assess the teaching procedure and develop the potential of the climate of motivation. This study 
aimed to conduct a preliminary validation of the "Motivational Climate in Physical Educational Scale" (MCPES) (Soini, Liukkonen, Watt, Yli-Piipari, \& Jaakkola, 2014) in the Greek educational context.

\section{Methods}

\section{Participants}

The sample of the study consists of 184 students of the last two grades from four elementary schools in different geographical areas of Greece (Imathia, Chanea, Kozani, and Rhodes) (Table 3). The selection of schools was randomly done. Initially, four prefectures from the country were chosen, and then the list was narrowed down to particular schools from these prefectures to which complete questionnaires were given for the survey.

\section{Instrument}

The Greek version of the MCPES (Soini, Liukkonen, Watt, Yli-Piipari, \& Jaakkola, 2014) was used. The questionnaire consists of eighteen items researching the four parameters of motivational climate during the PE lesson. The $1^{\text {st }}$ factor, "Autonomy support," consists of five items and examines the opportunities that PE provides to support students' independence, free choices, and the extent to which they can intervene in shaping the lesson (e.g., Students are given the opportunity to affect the way PE lessons are run.). The $2^{\text {nd }}$ factor, "Social relatedness support," consists of four items and traces the existence of team spirit and cooperation to meet the challenges of a lesson (e.g., During PE lessons, students "pull together."). The $3^{\text {rd }}$ factor, "Task-involving climate," consists of five items and considers any effort put into for personal improvement and the acceptance of errors as part of the learning procedure (e.g., It is important to keep trying even though you make mistakes.) The 4th factor, "Ego-involving climate," consists of four items and reviews the presence of competitive climate in the lessons, sense of superiority over classmates, and self-evaluation (e.g., During PE lessons, students compete with one another in terms of their performance), and this scale uses a Likert-type scale ranging from 1 (totally disagree) to 5 (totally agree).

The translation and amendment of the questionnaire in the Greek language were performed after considering the methodology (back-to-back translation technique) recommended by Banville, Desroriers, and Genet-Volet (2000).

The survey organizers had to ask for permission from the Ethics Committee of the Democritus University of Thrace and the Minister of Education to conduct the survey at schools. The approval was granted by the university in February 2019 and by the Ministry of Education a month later. The study was conducted in March and April 2019. Parental consent was asked to secure students' participation in the research. It was a written permit, and no data revealing the identity of the students for the completion of the questionnaires were required.

\section{Statistical Procedure}

For the statistical analysis of the data, the following methods were used: descriptive analysis (means, standard deviation, Kaiser-Meyer-Olkin (KMO) and Bartlett's test of sphericity and measure of sampling adequacy (MSA)), Exploratory factor analysis, reliability analysis (Cronbach's a), and one-way analysis.

\section{Results}

\section{Suitability of Data and Variables}

Researchers have affirmed that the first stage of a factorial analysis should explore the suitability of data and variables that are to be factorized because not all of them will do. This procedure involves checking the specific statistical index, such as a partial connection factor, which is controlled with the value of KMO, Bartlett's Test of Sphericity, and MSA (values that are near 1 indicate the suitability of variable).

Table 1. KMO and Bartlett's Test

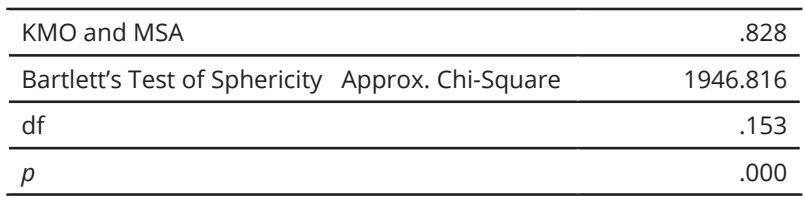

Table 1 demonstrates that the statistical criterion of $\mathrm{KMO}$ is high (.828), thereby suggesting that the connections between the data of the survey are high too. Moreover, Bartlett's Test of Sphericity declines the zero hypotheses that the connectivity table is unique (value Bartlett's Test of Sphericity Approx. Chisquare 1946.816, degree of freedom 153, and $p=.000$ ).

These findings displayed that the survey's data are appropriate for factorial analysis. However, for the examination of whether all the variables fit the model, the value of MSA was considered. According to the results, all the variables meet the suitability criterion, and the index fluctuates from .80 minimum to .89 maximum. Hair, Anderson, Tatham, and Black (1998) maintained that .9 and .8 are proper values, .7 and .6 are accepted but not very reliable, and values below .5 should be eliminated from the analysis.

\section{Exploratory Factor Analysis}

Eighteen questions relating to motivational climate are exploratory factors analyzed using principal component analysis solution with direct oblimin rotation. The analysis yields four factors explaining a total of $72.45 \%$ of the variance for the entire set of variables

The 1st factor "task involving" explains 19.95\% of the total variance and contains five items that examine the efforts to be made for personal improvement (Table 2). Factor one "task involvement" yields a subscale score of $M=4.03(S D=.94)(T a-$ ble 3). The 2nd factor "autonomy" accounts for $19.68 \%$ of the total variance, comprises five items, investigates the opportunities that PE provides to support students' autonomy (Table 2 ), and yields a subscale score of $M=3.24(S D=1.02$ ) (Table 3). The 3rd factor "social relatedness" explains $17.37 \%$ of the total variance and contains four items (Table 2 ) that investigate group mentality and collaboration to cope with the difficulties of a lesson. The 3rd factor yields a subscale score of $M=3.08$ $(S D=1.12)$ (Table 3). The 4th factor "ego involving" explains $15.46 \%$ of the total variance and comprises four items (Table 2 ) that investigates the antagonistic environment during a lesson. Factor four yields a subscale score of $M=2.43(S D=1.07)$ (Table 3).

\section{Reliability Analysis}

The internal cohesion of the questionnaire was checked with Cronbach's a test. The results support the structural validity of the questionnaire, and the factors were found to have a high degree of internal cohesion. Table 3 shows that the values of the factors are satisfactory $(a>.85)$ and presents the means and standard deviations of the main variables for the overall sample and for males and females. Generally, students perceived a high task-involving climate, relatively positive autonomy climate, moderate relatedness, and weak ego-involving climate.

\section{Differences in Relation to Gender}

For the determination of whether there are statistically significant differences in the scale factors between boys and girls, the one-way ANOVA analysis was conducted. The results showed that there were statistically significant differences for 
Table 2. Factor Analysis and Loadings for the 18-Item "MCPES" (Greek Version)

\begin{tabular}{|c|c|c|c|c|}
\hline \multirow[t]{2}{*}{ Items } & \multicolumn{4}{|c|}{ Factors } \\
\hline & $\begin{array}{c}\text { Task } \\
\text { involvement }\end{array}$ & Autonomy & $\begin{array}{c}\text { Social } \\
\text { relatedness }\end{array}$ & $\begin{array}{c}\text { Ego } \\
\text { involvement }\end{array}$ \\
\hline Students must try their best during PE lessons. & .83 & & & \\
\hline Learning new things makes me want to learn more. & .83 & & & \\
\hline Progressing every year in our skills is crucial. & .85 & & & \\
\hline Students must try to improve their skills. & .80 & & & \\
\hline It is important to keep trying even though you make mistakes. & .82 & & & \\
\hline Students have a significant role in decision making in PE lessons. & & 87 & & \\
\hline Students are given the opportunity to affect the way PE lessons are run. & & .85 & & \\
\hline Students have significant freedom to make choices during PE lessons. & & .86 & & \\
\hline Students are given the opportunity to select activities according to their interests. & & .84 & & \\
\hline Students can affect the course of PE lessons. & & .77 & & \\
\hline Our PE class has a good sense of unity. & & & .88 & \\
\hline Our PE class is united when practicing during PE lessons. & & & .86 & \\
\hline Students really "work together" as a team. & & & .84 & \\
\hline During PE lessons, students "pull together." & & & .90 & \\
\hline Students must show that they are better in PE than others. & & & & .78 \\
\hline During PE lessons, students compare their performance, mainly with that of others. & & & & .82 \\
\hline Students must succeed better than others. & & & & .80 \\
\hline During PE lessons, students compete with one another in terms of their performance. & & & & .84 \\
\hline \multicolumn{5}{|l|}{ Total variance: $72.45 \%$} \\
\hline \multicolumn{5}{|l|}{ Factors' variance } \\
\hline Eigen values & & & & \\
\hline
\end{tabular}

Table 3. Means, Standard Deviation, Cronbach's a and Statistically Significant Differences Between Boys and Girl

\begin{tabular}{lccccccccccc}
\hline & \multicolumn{2}{c}{ Overall $n=184$} & \multicolumn{2}{c}{ Male $n=101$} & \multicolumn{2}{c}{ Female $n=83$} & \multicolumn{2}{c}{ Statistical differences } & \multicolumn{2}{c}{ Cronbach's a } \\
\hline & $M$ & $S D$ & $M$ & $S D$ & $M$ & $S D$ & $f$ & $p$ & $n^{2}$ & alpha \\
\hline Task & 4.03 & .94 & 3.81 & 1.05 & 4.29 & .69 & 12.8 & .001 & .08 & .89 \\
\hline Autonomy & 3.24 & 1.02 & 3.44 & .99 & 2.99 & .99 & 9.40 & .001 & .05 & .89 & .90 \\
\hline Relatedness & 3.08 & 1.12 & 2.75 & 1.13 & 3.49 & .98 & 22.40 & .001 & .11 & .90 \\
\hline Ego & 2.43 & 1.07 & 2.78 & 1.20 & 2.02 & .71 & 24.60 & .001 & .12 & .85 \\
\hline
\end{tabular}

the factors "task involving climate" $\left[F_{(1,183)}=12.8 ; p<.001\right.$, $\left.n^{2}=.08\right] ;$ "autonomy" $\left[F_{(1,183)}=9.40 ; p<.001, n^{2}=.05\right] ;$ "relatedness" $\left[F_{(1,183)}=22.4 ; p<.001, n^{2}=.11\right]$; and "ego involving climate" $\left[F_{(1,183)}=24.6 ; p<.001, n^{2}=.12\right]$. More specifically, the results indicate that (a) male students presented a statistically higher score $(M=3.44$ and $S D=.99)$ regarding the factor "autonomy" in relation to female students $(M=2.99$ and $S D=.99)$, (b) male students presented a statistically higher score $(M=2.78$ and $S D=1.20)$ regarding the factor "ego involving climate" in relation to female students $(M=$ 2.01 and $S D=.71$ ), (c) female students presented a statistically higher score $(M=4.29$ and $S D=.69)$ regarding the factor "task involving climate" in relation to male $(M=3.81$ and $S D=1.05)$, and (d) female students presented a statistically higher score $(M=3.49$ and $S D=.98)$ regarding the factor "relatedness" in relation to male students $(M=2.75$ and $S D$ = 1.13) (Table 3).

\section{Discussion}

One of the main objectives of PE is students' motivation for active participation in the lesson, which for many, is the result of the motivation climate that prevails during the learning process. Students' active involvement is essential and a basic requirement to fulfill the potential of lifelong exercise. Consequently, a PE teacher needs an instrument to monitor the effort that a student makes to enhance his performance in a lesson. Therefore, this study aimed to update the ques- tionnaire MCPES (Soini et al., 2014) in the Greek educational context and to look into gender as a differentiation factor of the motivational environment.

Regarding the validity of the factors and the structure itself, MCPES has shown a structure of four oblique factors, coinciding with the findings of Soini et al. (2014). As far as reliability is concerned, results have shown the required internal consistency and temporal stability of the scale, with results similar to the findings of Soini et al. (2014) (Cronbach's a autonomy $=.85$, relatedness $=.88$, task $=.80$, and ego $=.78)$ and Jaakkola, Wang, Soini, and Liukkonen (2015) (Cronbach's $a$ autonomy $=.85$, relatedness $=.88$, task $=.80$, and ego $=.78$ ).

PE teachers and the teaching methods they adopt appear to shape a motivational environment focused on learning itself and on instilling a sense of autonomy among students because the factors "task involving" and "autonomy" have the highest score. Moreover, the lesson favors the development of social bonds and cooperation as the factor relatedness is relatively high. By contrast, the factor ego comes at the bottom of the table. The findings of the study justify the writers' claim that PE educators succeed in their ultimate aim to achieve lifelong exercise through the program given that those who are determined to take their fitness level to a higher level usually continue doing so with patience and commitment for a long time regardless of their views on the matter (Papaioannou, Theodorakis, \& Goudas, 2003). 
Gender proves a differentiation factor of the motivational environment. Males, in particular, are more independent and self-oriented, unlike females who are more sociable and task-oriented. The results of the study coincide with those of Castro-Sánchez, Zurita-Ortega, Garcia-Marmol, and Chacón-Cuberos (2019) who stated that for boys' collaboration is not their first priority because they believe that they can cope on their own no matter how complicated a problem may be. Conversely, girls cooperate effort lastly and develop social relationships. The results of the survey partly match those of Jaakkola, Wang, Soini, and Liukkonen (2015), but it also negates it. They agree that boys are more autonomous and ego-involved $\left(M_{\text {autonomy }}=3.02\right.$ and ego $\left.=3.24\right)$ from girls $(M$ $=2.91$ and ego $=2.86$ ). Nevertheless, Jaakkola, Wang, Soini, and Liukkonen (2015) suggested that boys are more sociable $(M=3.23)$ than girls $(M=3.11)$ and that there is no difference between the genders regarding task-involving climate. Any disparities between the surveys might arise from the different age samples as the Jaakkola, Yli-Piipari, Barkoukis, and Liukkonen (2017) work involved 15 years old students ( $9^{\text {th }}$ graders) and the current $11-12\left(5^{\text {th }}\right.$ and $6^{\text {th }}$ graders).

Given the survey and the discussion, the following conclusions can be drawn:

a. The Greek version of MCPES is established as a reliable measuring instrument of the climate of motivation in the field of primary education in Greece.

b. Gender is a differentiation factor of the climate of motivation with, male students obtaining scores higher in ego involving and autonomy and female students performing better in a task involving and relatedness.

\section{Funding Acknowledgement}

The authors received no financial support for the research, authorship, and publication of this article.

\section{References}

Banville, D., Desroriers, P., \& Genet-Volet, Y. (2000). Translating questionnaires and Inventories using a cross-cultural translation technique. Journal of Teaching in Physical Education, 19, 374-387.

Bournelli, P., Koutsouki, D., Zografou, M., Aggelonidis, I., Chatzopoulos, D., \& Agalianou, O. (2012). Physical Education for 3rd \& 4th elementary school grades. Teacher's book. Athens. Textbook Publishing Organization.

Castro-Sánchez, M., Zurita-Ortega, F., Garcia-Marmol, E., \& Chacón-Cuberos, R. (2019). Motivational Climate towards the Practice of Physical Activity, Self-Concept, and Healthy Factors in the School Environment. Sustainability, 11(4), 999. https://doi.org/10.3390/ su11040999.

Cid, L., Pires, A., Borrego, C., Duarte-Mendes, P., Teixeira, D., Moutão, Z., \& Monteiro, D. (2019). Motivational determinants of physical education grades and the intention to practice sport in the future. PLOS ONE, 14(5): e0217218. https://doi.org/10.1371/journal. pone. 0217218

Colquitt, G., Walker, A., Langdon, J.L., McCollum, S., \& Pomazal, M. (2012). Exploring student attitudes toward physical education and implications for policy. Sport Scientific \& Practical Aspects, 9(2), 5-12.

Fox, K. (1992). Education for exercise and the national curriculum proposals: A step forward or backwards. British Journal of Physical Education, 23(1), 8-11.
Ghofrani, M., \& Golsanamlou, M. (2012). Students' perception of physical education courses and its relationship with their participation in sport activities. Sport Scientific \& Practical Aspects, 9(1), 21-31.

Hagger, M. S., \& Chatzisarantis, N. L. (2007). Intrinsic motivation and self-determination in exercise and sport. Champaigne, IL: Human Kinetics.

Hair, J., Anderson, R., Tatham, R.L., \& Black, W.C. (1998). Multivariate data analysis, (5th ed.), NJ: Upper Saddle River, Prentice-Hall.

Iconomescu, M., Mindrescu, V., \& Popovici, I. (2018). A comparative study regarding secondary school students' satisfaction degree regarding the physical education class in Romanian and in Turkey. SHS Web of Conferences, 48, 01028, https:// doi.org/10.1051 / shsconf/20184801028.

Institution of Educational Policy. 21 century , contemporary school, New curriculum. Teacher's guide. Athens. http://repository.edulll.gr/edulll/handle/10795/1892.

Jaakkola, T., Yli-Piipari, S., Barkoukis, V., \& Liukkonen, J. (2017). Relationships among perceived motivational climate, motivational regulations, enjoyment, and PA participation among Finnish physical education students. International Journal of Sport and Exercise Psychology, 15(3), 273-290. http://10.1080/ 1612197X.2015.1100209.

Jaakkola, T., Wang, J., Soini, M., \& Liukkonen, J. (2015). Students' Perceptions of Motivational Climate and Enjoyment in Finnish Physical Education: A Latent Profile Analysis. Journal of Sports Science and Medicine, 14(3), 477-483.

Koundouras, St. (2017). The Impact of Motivational Climate and Basic Psychological Needs on the Formation of Beliefs for Leisure-Time Physical Activity in Primary School Students (Postgraduate dissertation). Available: http://ikee.lib. auth.gr/record/292932? In=el

Morgan, K. (2017). Reconceptualizing Motivational Climate in Physical Education and Sport Coaching: An Interdisciplinary Perspective. QUEST, 69(1), 95-112. http://dx.doi. org/10.1080/00336297.2016.1152984.

Ntoumanis, N., Barkoukis, V., \& Thøgersen-Ntoumani, C. (2009). Developmental trajectories of motivation in physical education: Course, demographic differences, and antecedents. Journal of Educational Psychology, 101(3), 717-728. http://dx.doi.org/10.1037/a0014696.

Papaioannou, A., Theodorakis, I., \& Goudas, M. (2003). For a better Physical Education. Thessaloniki: Christodoulidi. Parissi, I., Mouratidou, K., Koidou, E., Tsorbatzoudis, H., \& Karamavrou, S. (2015). Effects of motivational climate, type of school and gender on students' moral competences in their daily life and physical education. TRENDS in Sport Sciences, 1(22): 39-46.

Soini, M., Liukkonen, J., Watt, A., Yli-Piipari, S., \& Jaakkola, T. (2014). Factorial validity and internal consistency of the motivational climate in physical education scale. Journal of Sports Science \& Medicine, 13(1), 137-144.

Treasure, D.C., \& Roberts, G.C. (1995). Applications of Achievement Goal Theory to Physical Education: Implications for Enhancing Motivation. Quest, 47(4), 475-489. DOl: 10. 1080/00336297. 1995.10484170. 